\title{
Interaction and Music Technology
}

\author{
Sidney Fels ${ }^{1}$ and Michael Lyons ${ }^{2}$ \\ ${ }^{1}$ Dept. of Electrical and Computer Engineering, University of British Columbia, \\ 2356 Main Mall, Vancouver, BC, Canada V6T 1Z4 \\ ssfels@ece.ubc.ca \\ ${ }^{2}$ College of Image Arts and Science, Ritsumeikan University, \\ 56-1 Tojiin Kitamachi Kita-ku Kyoto Japan 603-8577 \\ lyons@im.ritsumei.ac.jp
}

\begin{abstract}
This SIG intends to investigate the ongoing dialogue between music technology and the field of human-computer interaction. Our specific aims are to explore major findings of specialized musical interface research over recent years and convey these to HCI researchers who may be interested but not yet active in this area, as well as to consider how to stimulate closer cooperation between music technology and HCI research communities.
\end{abstract}

Keywords: Music, Technology, Interactive Techniques, HCI.

\section{Introduction}

Advances in digital audio technologies have led to a situation where computers now play a role in most music production and performance. Digital technologies offer unprecedented opportunities for the creation and manipulation of sound, however the flexibility of these new technologies implies a confusing array of choices for composers and performers. Some musicians have embraced this challenge by using computers directly to create music, leading to an ongoing development of new musical forms. However, most would agree that the computer is not a musical instrument, in the same sense as traditional instruments, and it is natural to seek to design interfaces which allow the computer to be 'played' in fashion suited for human bodies and brains. A decade ago we organized a workshop on "New Interfaces for Musical Expression" [1] at the ACM CHI 2001 conference, with the aim of addressing this issue by exploring connections with the better established field of human-computer interaction. The workshop soon developed into an annual international conference (NIME), which attracts several hundred participants every year. NIME is now considered to be a major venue for the publication of advances in music technology, with an emphasis on methodology and technology from the broader field of human-computer interaction.

\section{Relevance to INTERACT 2011}

The authors recently began a series of outreach activities [2] to bring a summary of findings of the first ten years of the NIME conference to the attention of the broader 
research community in human-computer interaction. While some of the members of the music technology research community continue to participate in HCI-related conferences such as CHI and INTERACT, presence of music technology related studies at these conferences is relatively sparse in view of the broad interest in music and its importance for emerging technologies. Moreover we feel that some of the important findings being presented at NIME could be of general interest to researchers who may not have a specific focus on music-related projects.

We therefore propose to invite any participants of INTERACT 2011 who may be interested in music as a potential domain for the study of human-computer interaction to join us for a discussion exploring the past, present, and future dialogue between interaction and music technology.

\section{Format of the Discussion}

This SIG meeting will consist of a structured discussion addressing several topics of shared interest in the music technology and HCI research communities. Topics for discussion include, but are not expressly limited to the following:

- Design and Aesthetics of musical interface design

- Tools for prototyping new music technology

- Methodologies for evaluating musical interfaces

- Models of 'Playability' of new musical interfaces

- Theories of human action and perception in musical performance

- Mobile music making

- Collaborative music making

- Networked music making

- Music technology for novices

- Musical interfaces in the HCI Curriculum

- Future of Music, Technology, and HCI

- How to better represent music themed research in the HCI community

\section{References}

1. Poupyrev, I., Lyons, M.J., Fels, S., Blaine, T.: New interfaces for musical expression. In: CHI 2001 Extended Abstracts on Human Factors in Computing Systems (CHI EA 2001), pp. 491-492. ACM, New York (2001)

2. Fels, S., Lyons, M.: Creating new interfaces for musical expression: introduction to NIME. In: ACM SIGGRAPH 2009 Courses (SIGGRAPH 2009), Article 11, 158 pages. ACM, New York (2009) 